\title{
Experiences of Light in Gay and Lesbian Near-Death Experiences
}

\author{
Liz Dale, Ph.D. \\ San Pablo, CA
}

ABSTRACT: This article illustrates the concept of divine light in stories of gay, lesbian, bisexual, and transgender near-death experiencers.

KEY WORDS: near-death experience; gay/lesbian/bisexual/transgender; spirituality; divine light.

In Crossing Over and Coming Home, I recorded numerous personal accounts of near-death experiences (NDEs) from within the gay/ lesbian/bisexual/transgender (GLBT) community (Dale, 2001). In his endorsement of that book, Stanislav Grof wrote that the "study of neardeath experiences in the gay community ... is also a major contribution to the general understanding of the phenomenology of near-death states and their effects on survivors" (Grof, 2001, unpaged frontispiece).

Before describing examples of the impact of divine light within gay NDEs, let me address the reason it is important to document GLBT near-death stories. Christian de la Huerta wrote in his groundbreaking book, Coming Out Spiritually, that there was a time when gay people "were the shamans, the healers, the visionaries, the mediators, the peacekeepers, the 'people who walk between the worlds,' the keepers of beauty" (1999, p. 3). As can be seen by the following excerpts from their stories, the men and women who wrote accounts of their NDEs were very courageous. Melvin Morse wrote:

The near-death experiences that gays and lesbians report are powerful reminders that all human beings share a common truth: We will have near-death experiences when we die .... Gay or straight,

Liz Dale, $\mathrm{Ph} . \mathrm{D}$., is a clinical psychologist in private practice. Reprint requests should be addressed to Dr. Dale at 95 Christine Court, San Pablo, CA 94806; e-mail: lizdale1@juno.com. 
brown skin or white skin, or rich and poor alike, we will all have one when we die. (Morse, 2001, p. i)

The concept of light is one of the key images one experiences in an NDE. The Dalai Lama described the metaphor of light as:

a common image in all the major religious traditions. In the Buddhist context, light is particularly associated with wisdom and knowledge; darkness is associated with ignorance and a state of misknowledge. (1999, p. 304)

Within the stories of the GLBT near-death experiences, divine light is an essential component. The majority of GLBT near-death experiencers whose accounts I collected ( 73 percent) reported such experiences. For example, one experiencer who had taken an overdose of sleeping pills and alcohol wrote the following:

All of a sudden I felt as though I was moving through a corridor. It was dark but not at all frightening. I sensed the presence of others. Some of these "spirit entities" were moving more slowly than others toward the light .... Suddenly, I was in a place that appeared to be room suffused with light. There were no walls or ceilings or floors.

Light seemed to extend into infinity. (Dale, 2001, p. 100)

GLBT near-death experiencers offered a reason for the presence of light. The majority of experiencers whose accounts I collected (73 percent) felt a sense of comfort within the light. The divine light emanated either from the NDEr or from others in the NDE scenery. One woman described her childhood NDE from a near-drowning in the following way:

I do not remember struggling or being afraid. I felt only deep peace and happiness. While my body was at the bottom of the river, I remember looking up toward the surface. I enjoyed watching a beautiful array of dancing, brilliant sparkles of color from the yellow sunlight coming through the river water. I was calm and fascinated by the beauty of the light and the reeds coming through the mud. (Dale, 2001, p. 40)

These GLBT NDE stories illustrate the message of a powerful connection between light, love, and spirituality, over and over. Why do GLBT near-death experiencers consider the NDE to be so inspiring? Historically, there was a time when gays and lesbians were looked upon favorably by society. But in recent times, quoting again from de la Huerta:

Many [gays] have attempted to reject their spirituality - a tragic and fruitless endeavor as ludicrous as waking up one day and deciding 
that one no longer needs to breathe because someone, somewhere decreed that breathing is an evil, sick, sinful or immoral act. (de la Huerta, 1999, p. 5)

Malidoma Patrice Somé of the Dagara tribe of Burkina Faso described gays as having a higher "vibrational" level that enables them to be guardians of the gateways of the spirit world. In an interview in 1993 at the Mendocino Men's Conference, he described indigenous people's view of gay men:

[A]t least among the Dagara people, gender has very little to do with anatomy. It is purely energetic. In that context, a male who is physically male can vibrate female energy, and vice versa. That is where the real gender is .... In the culture that I come from ... these people are looked on, essentially, as people ....

The earth is looked at, from my tribal perspective, as a very, very delicate machine or consciousness, with high vibrational points, which certain people must be guardians of in order for the tribe to keep its continuity with the gods and with the spirits that dwell there .... Any person who is at this link between this world and the other world experiences a state of vibrational consciousness which is far higher, and far different, from the one that a normal person would experience. This is what makes a gay person gay. (Somé, cited in Hoff, 1993, pp. 1-2)

The GLBT persons whose accounts I collected "came out of the closet," so to speak, so that we can all see what is true and beautiful to the NDE: that there is a world just beyond this one in which all people, regardless of skin color, gender, age, lifestyle, or sexual orientation, are viewed as equal. The crosscultural context within each of these stories, although highly valuable to the reader of NDE accounts, can reveal more than some GLBTs would be willing to expose. For instance, when it came time to publish my book, some of the contributors refused to have their stories published. Although the accounts were all anonymous, some potential authors felt that there might be a way they could be identified or that there was something "wrong" with recording such spiritual stories. Unfortunately, these stories have remained unpublished.

The GLBT NDE stories I have collected contain account after account of deeply meaningful experiences. Some of the most deeply inspiring of these accounts provide examples of this newfound spiritual growth. For example, one man who had had an NDE during an extended coma following an emergency appendectomy at age 17, wrote:

I will say that my near-death experience dramatically changed who I was and how I lived. I live not by what I read and "think" is right; I 
live by what I "know" is right for me. This doesn't mean that it's right for you. I still go to church and worship God but God doesn't "need" people to worship Him. One doesn't have to do anything to go to heaven ....

We are here on earth to learn from each other and help each other. If we want to "learn," we must keep an open mind.

Just like everyone else here, I am not simply a human being. I am a spirit with a human shell. Someday I will leave my body and continue in the spiritual, non-material realm again. (Dale, 2001, p. 121)

I would like to conclude this paper with a perspective on the concept of divine light from Ken Wilbur's Sex, Ecology, Spirituality:

The observer in you, the Witness in you, transcends the isolated person in you and opens instead - from within or from behind, as Emerson said - onto a vast expanse of awareness no longer a respecter or abuser of persons, no longer fascinated by the passing joys and set-apart sorrows of the lonely self, but standing still in silence as an opening or clearing through which light shines, not from the world but into it - "a light shines through us upon things." That which observes or witnesses the self, the person, is precisely to that degree free of the self, the person, and through that opening comes pouring the light and power of the Self, a Soul, that as Emerson puts it, "would make our knees bend." (2000, p. 289)

\section{References}

Dalai Lama. (1999). The path to tranquility. New York, NY: Penguin Putnam.

Dale, L. (2001). Crossing over and coming home: Twenty-one authors discuss the gay near-death experience as spiritual transformation. Houston, TX: Emerald Ink.

de la Huerta, C. (1999). Coming out spiritually. New York, NY: Tarcher/Putnam.

Grof, S. (2001). [Endorsement]. In Dale, L., Crossing over and coming home (unpaged frontispiece). Houston, TX: Emerald Ink.

Hoff, B. H. (1993, September). Gays: Guardians of the gates [an interview with Malidoma Somé]. Men Magazine, pp. 1-2. Retrieved October 19, 2005, from the

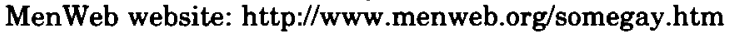

Morse, M. (2001). Foreword. In Dale, L., Crossing over and coming home (pp. i-iii). Houston, TX: Emerald Ink.

Wilbur, K. (2000). Sex, ecology, spirituality. Boston, MA: Shambhala. 